\title{
Attitudes towards treatment among patients suffering from sleep disorders. A Latin American survey
}

\author{
Margarita Blanco ${ }^{1}$, Norberto Kriguer ${ }^{2}$, Santiago Pérez Lloret $^{3}$ and \\ Daniel P Cardinali*3
}

Address: ${ }^{1}$ Neurofisiología Clínica y Medicina del Sueño, Centro Neurológico, Hospital Francés, Buenos Aires, Argentina, ${ }^{2}$ Centro de Sueño y Síndrome de Fatiga Crónica, Buenos Aires, Argentina and ${ }^{3}$ Departamento de Fisiología, Facultad de Medicina, Universidad de Buenos Aires, Argentina

Email: Margarita Blanco - margarita.blanco@sion.com; Norberto Kriguer - nkriguer@intramed.net.ar; Santiago Pérez Lloret - thiago@sinectis.com.ar; Daniel P Cardinali* - cardinal@mail.retina.ar

* Corresponding author

\begin{abstract}
Background: Although sleep disorders are common, they frequently remain unnoticed by the general practitioner. Few data are available about the willingness and reasons of patients with sleep disturbances to seek for medical assistance.

Methods: The results of a cross-sectional community-based multinational survey in three major Latin American urban areas, i.e. Buenos Aires, Mexico City and Sao Paulo, are reported. Twohundred subjects suffering sleep disturbances and 100 non-sufferers were selected from the general population in each city (total number: 600 sufferers vs. 300 non-sufferers). A structured interview was conducted, sleep characteristics, feelings about sleep disturbances and strategies to cope with those problems being recorded. Data were analyzed by employing either t-test or analysis of variance (ANOVA) to the Z-transformed proportions.

Results: $22.7 \pm 3.5 \%$ (mean \pm SEM) of subjects reported to suffer from sleep disturbances every night. About 3 out of $4(74.2 \pm 2.0 \%)$ considered their disorder as mild and were not very concerned about it. Only $3 \mathrm{I} \pm 2 \%$ of sufferers reported to have sought for medical help. Although $45 \pm 2 \%$ of sufferers reported frequent daily sleepiness, trouble to remember things, irritability and headaches, they did not seek for medical assistance. Among those patients who saw a physician with complaints different from sleep difficulties only I out of 3 (33 $\pm 2 \%$ of patients) were asked about quality of their sleep by the incumbent practitioner. Strategies of patients to cope with sleep problems included specific behaviors (taking a warm bath, reading or watching TV) (44 $\pm 1.6 \%$ ), taking herbal beverages ( $17 \pm 1.2 \%)$ or taking sleeping pills $(10 \pm 1.1 \%)$. Benzodiazepines were consumed by $3 \pm 0.6 \%$ of sufferers.
\end{abstract}

Conclusion: Public educational campaigns on the consequences of sleep disorders and an adequate training of physicians in sleep medicine are needed to educate both the public and the general practitioners about sleep disorders. 


\section{Background}

Sleep disorders are very frequent among general population. Surveys of outpatients visiting primary care centers indicate that the prevalence of sleep disturbances varies between 25 and $45 \%$ [1-3]. In $66 \%$ of sufferers sleep problems occur almost every night [4]. Sleep disturbances are perceived as mild or moderate by the majority of sufferers. However, they are important enough to affect patients' quality of life [5].

Diagnosis and treatment of sleep disturbances should be considered as a matter of public concern. On one hand, several illnesses or conditions have as co-morbidities an alteration of sleep. This is the case of psychiatric diseases, like anxiety or depression [6,7], post-traumatic stress [8] or neurological diseases, e.g. headache [9] or Parkinson's disease [10]. The risk of stroke is greater among sufferers of poor sleep by sleep apnea $[11,12]$. Additionally, daily sleepiness results in long term impairment of work capacity [13] and increased risk of car accidents [14,15].

General practitioners and family physicians are at an ideal position to perform surveillance over sleep problems. Yet, many patients never get to talk about their disturbances with their physician. Some authors reported that the frequency of complaints about sleep could be as high as 30 $\%$, especially among mildly affected subjects $[1,5,16]$. When noticed, the most common strategy treatment chosen by practitioners is pharmacological [17], thus raising concern about the excessive prescription and utilization of hypnotics [18].

Some evidence supports the notion that the reason for sleep disturbances to be unnoticed by physicians is that they are not specifically looked for [19-25]. In order to obtain information on the attitudes and beliefs of patients in urban Latin American areas towards their sleep problems and about their willingness to receive appropriate treatment the present survey was conducted in three Latin American cities: Buenos Aires, Mexico City and Sao Paulo.

\section{Methods \\ Population studied}

The Latin American Sleep Society, in conjunction with ACNielsen BASES, Covington, Kentucky, USA, conducted a telephone and door-to-door interviews with a sample of adults living in main urban areas of Buenos Aires, Mexico City and Sao Paulo (final number of interviews: 200 sufferers and 100 non-sufferers in each City). Adults were randomly selected from the phone book and interviews continued until the desired sample size was reached. The sample size was determined on the basis of a previously conducted interview in 1776 subjects in which it was found that nearly $66 \%$ of them reported to have a sleep disorder. All subjects were interviewed by trained assist- ants with a structured questionnaire (paper-pencil version). Refusal rate in the sample, i.e. those subjects who refused to participate either verbally or by their absence of reply, was $27 \%$.

To qualify, respondents must have experienced any of the following in the past 3 months: have difficulty falling asleep, wake up in the middle of the night, have difficulty falling back to sleep, wake up too early in the morning, wake up feeling drowsy or tired. Non-sufferers were defined as those who had not experienced any of the above in the past 3 months.

\section{Survey}

A structured questionnaire about sleep disturbances was employed. Subjects were asked to classify themselves as having chronic or occasional sleep disorder. This was arbitrarily defined by dichotomizing the sample as chronic (having sleep problems every night) vs. occasional (having problems less than every night. To assess night-time sleep difficulties, participants were asked to rate on a scale (from $1=$ never to $7=$ always) how often they had trouble with the following aspects of their sleep based on the previous 12 months: (1) falling asleep at night, (2) waking up during the night, (3) waking up and getting up in the morning, and (4) waking up too early and not being able to fall asleep again. Four levels of concern/severity were considered: "severely affected" (those individuals in 7, 6 and 5 rating of severity scale and who were very concerned); "moderately affected" (those individuals in 7, 6, 5 and 4 rating of severity scale and who were very/somewhat concerned); "mildly affected" (those individuals who considered their problem either severe and were not concerned, or not severe and were concerned); "not affected" (those individuals in 3, 2 and 1 rating of severity scale and who were not very or at all concerned). Willingness to seek medical help among sufferers as well as the frequency at which the sleep disorder was specifically looked for the physicians when the patients consulted them for causes unrelated to sleep were also assessed by direct questioning. Those subjects who were not willing to seek for medical help, where asked to state the reason for their behavior as: 1) feeling the problem was not serious enough; 2) fear to receive pharmacological therapy and become addicted to drug; 3 ) other reasons. Then, subjects were asked to describe which strategy they employed to deal with sleep problems. The answers were classified as pharmaceutical or non-pharmaceutical strategies or other (behavioral). Frequency of drowsiness during car driving and the strategies employed for avoiding dozing off while driving were also investigated.

\section{Statistical analysis}

Data were analyzed by employing either t-test or analysis of variance (ANOVA) to the Z-transformed proportions. 
Table I: Attitudes and beliefs of sufferers towards their sleep disturbances.

\begin{tabular}{lc}
\hline & Sufferers \\
\hline Sample size (women) & $600(310)$ \\
Sought doctor's advice & $31 \pm 1.9 \%$ \\
Doctor assessed sleep disturbances & $33 \pm 1.9 \%$ \\
Barriers to seeking medical help & \\
$\quad$ Not considering the problem serious enough & $45 \pm 2.0 \%$ \\
$\quad$ Fear to become addicted & $8 \pm 1.1 \%$ \\
Strategies to cope with sleep disturbances & \\
Behavioral & $67 \pm 1.9 \%$ \\
Non-pharmaceutical & $27 \pm 1.8 \%$ \\
Pharmaceutical & $14 \pm 1.4 \%$ \\
$\quad$ Do nothing & $19 \pm 1.6 \%$ \\
Reason for not employing prescribed drugs & $67 \pm 2.0 \%$ \\
$\quad$ Fear to become addicted & $35 \pm 2.0 \%$ \\
Considering sleep disorder not serious enough & $19 \pm 1.6 \%$ \\
Fear to feel drowsy or tired next day & $16 \pm 1.5 \%$ \\
\hline
\end{tabular}

ANOVA was followed by Dunnett's post-hoc test. Data were analyzed only when the products of $\mathrm{n}$ and $\mathrm{p}$ as well as $\mathrm{n}$ and (1-p) were no less than 5 .

\section{Results}

There were no significant differences in results among the three urban areas examined. Therefore the results are presented as a single population. In the sample examined $22.7 \pm 3.5 \%$ (mean \pm SEM) of subjects reported to suffer from a sleep disturbance almost every night. About 3 out of $4(74.2 \pm 2.0 \%)$ considered their disorder as mild and were not very concerned about it. Only $31 \pm 1.9 \%$ of sufferers sought for medical help while physicians assessed presence of sleep disorder in only $33 \pm 1.9 \%$ of those patients consulting them for causes other than sleep disturbances (Table 1). In both cases frequencies were significantly higher in chronic sufferers and in those reporting moderate or severe sleep disturbances (Fig. 1).

Marital status, gender and socioeconomic status were similar among chronically or occasionally affected sufferers and non-sufferers. No difference was found when variables were analyzed according to level of concern (results not shown). The proportion of patients suffering from any other chronic diseases, not related to sleep, was greater in the chronically affected group as compared to occasionally affected or non-sufferers $(36 \pm 4.1 \%, 21 \pm 1.9$ and 15 \pm 2.0 , respectively, ANOVA followed by Dunnett's test). Accordingly, severely and moderately affected sufferers reported more frequency of chronic diseases not related to sleep as compared to mildly and non-affected sufferers (respectively, $41 \pm 6 \%, 33 \pm 5.1,24 \pm 2.7$ and $17 \pm 2.6$, ANOVA followed by Dunnett's test).
Not considering the problem serious enough and fear to become addicted to medication were the reasons for not seeking medical help most frequently mentioned (Table 1 ). The former reason was most frequently adduced by occasional sufferers and those mildly, moderately or not affected, whereas fear of addiction was most frequently mentioned by severely affected sufferers.

Behavioral (i.e. watching TV, listening to music, reading, taking a hot bath, etc.), non-pharmaceutical or pharmaceutical strategies were employed to cope with the sleep difficulties by 44,17 and $10 \%$ of sufferers, respectively (Table 1). No differences in strategies were found between chronic vs. occasional sufferers, nor according to degree of affection, except for the pharmaceutical strategy, which was most frequently employed by chronic sufferers ( $15 \mathrm{vs.}$ $8 \%$ in occasional sufferers, Fig. 2). Benzodiazepines were consumed by $3 \pm 0.6 \%$ of patients.

The most frequently reason for not employing prescribed drugs adduced by patients was fear to turn addicted to medication (Table 1). Considering their sleep problem not serious enough, fear to feel drowsy or tired next day and unwillingness to get medical help were also adduced (Table 1). Fear of addiction, difficulty not severe enough to worry about and feeling medication unnatural were significantly more frequently mentioned by occasional sufferers as compared to chronic sufferers (Fig. 3). Skewing towards some of the responses may not invalidate the conclusions, since those responses did not exclude the others. 


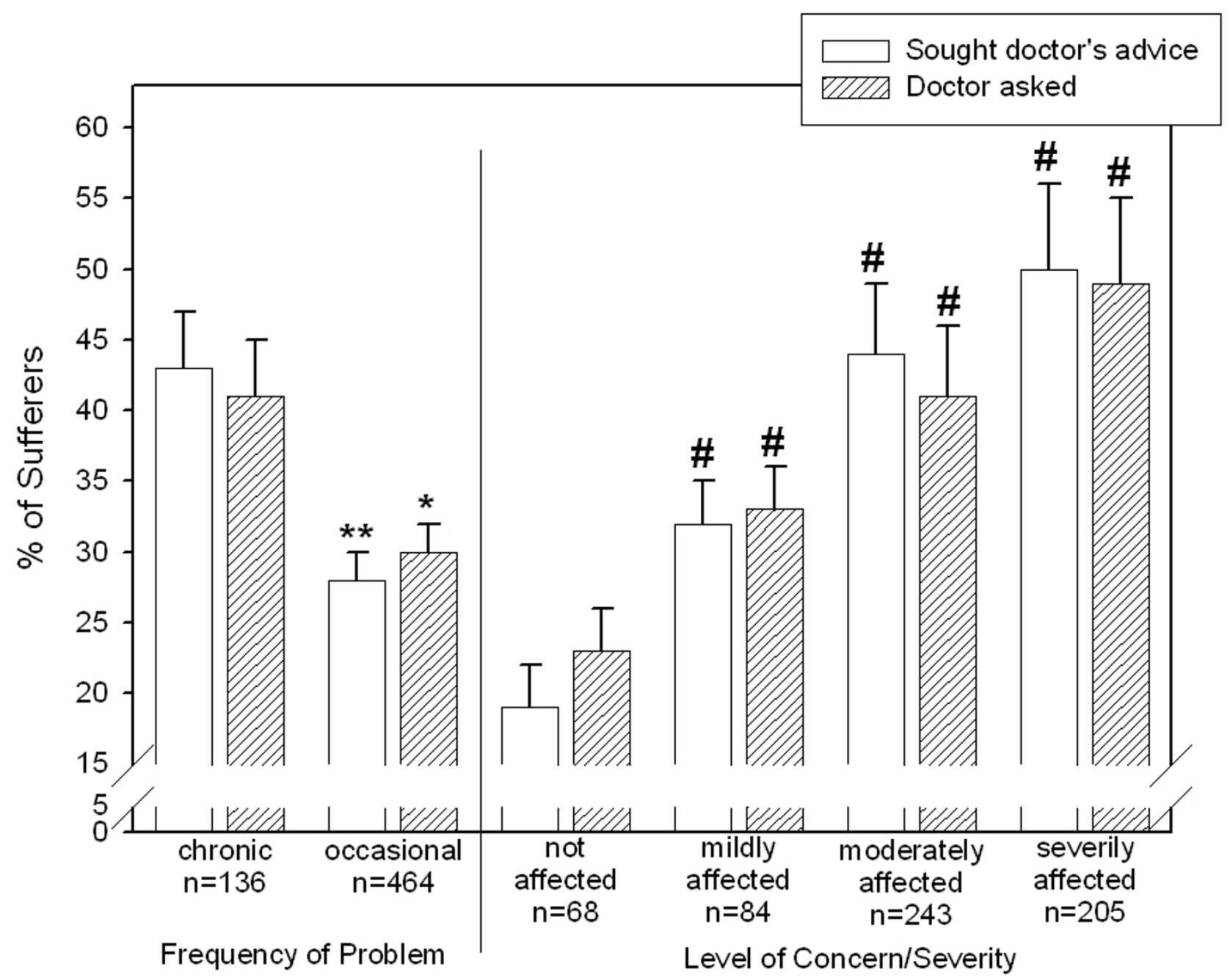

Figure I

Percent of sufferers who sought for medical help for their sleep disturbances and of patients asked about quality of their sleep by the physician, according to frequency of problem or level of concern/severity. Shown are the means + SEM. * $p<0.01$, ** $p<0.001$ vs. chronically affected sufferers (t-test for proportions), \# $p<0.05$ vs. not affected sufferers (one-way ANOVA, Dunnett's post-hoc test).

Drowsiness during car driving was assessed in both sufferers and non-sufferers. Among the former, drowsiness was more frequently found. Additionally, significantly more sufferers reported not driving a car.

As shown in Fig. 4, sufferers experienced a significantly higher frequency of episodes of daily sleepiness, troubles to remember things, headaches and irritability as com- pared to non-sufferers. Among sufferers, $76 \pm 1.7 \%$ and $62 \pm 2.0 \%$ stated that they believed that sleep problems could impair their performance at work or led to other health problems, respectively.

\section{Discussion}

Foregoing results, derived from a community-based multinational structured survey on sleep disturbances in a 


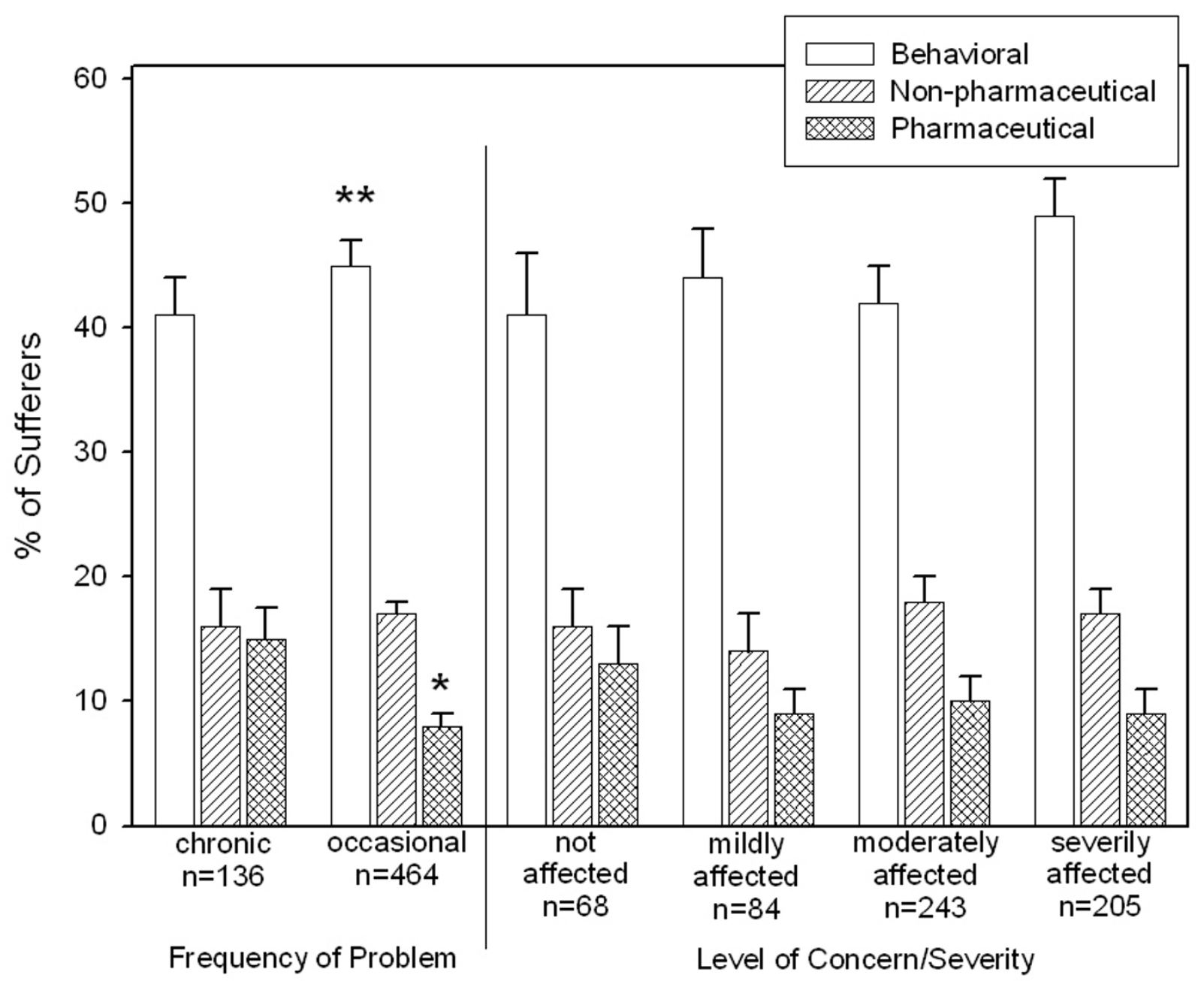

Figure 2

Strategies employed by sufferers to cope with their sleep disturbances. Shown are the means + SEM. $* p<0.05$ vs. chronically affected sufferers (t-test for proportions).

Latin American urban population, indicated that only a small part of sufferers sought medical help for their problem or was questioned about them by the attending physician. Although experiencing significantly lower quality of life (i.e. daily sleepiness, trouble remembering things, headaches and irritability) and being more prone to carrelated accidents, at least half of sufferers avoided seeking for medical help. Instead, non-medical strategies were employed by 2 out of 3 sufferers.
Sleep disturbances are generally overlooked by physicians. For example, when presented with a theoretical standard case of sleep disorder, less than $50 \%$ of physicians employed a sleep history to record the symptoms [26]. Accordingly, we found that only $30 \%$ of sufferers visiting their doctors for causes different to sleep difficulties were surveyed about them. Since these problems can be easily treated by general practitioners without the need of a specialist [27], an effective educational campaign to 


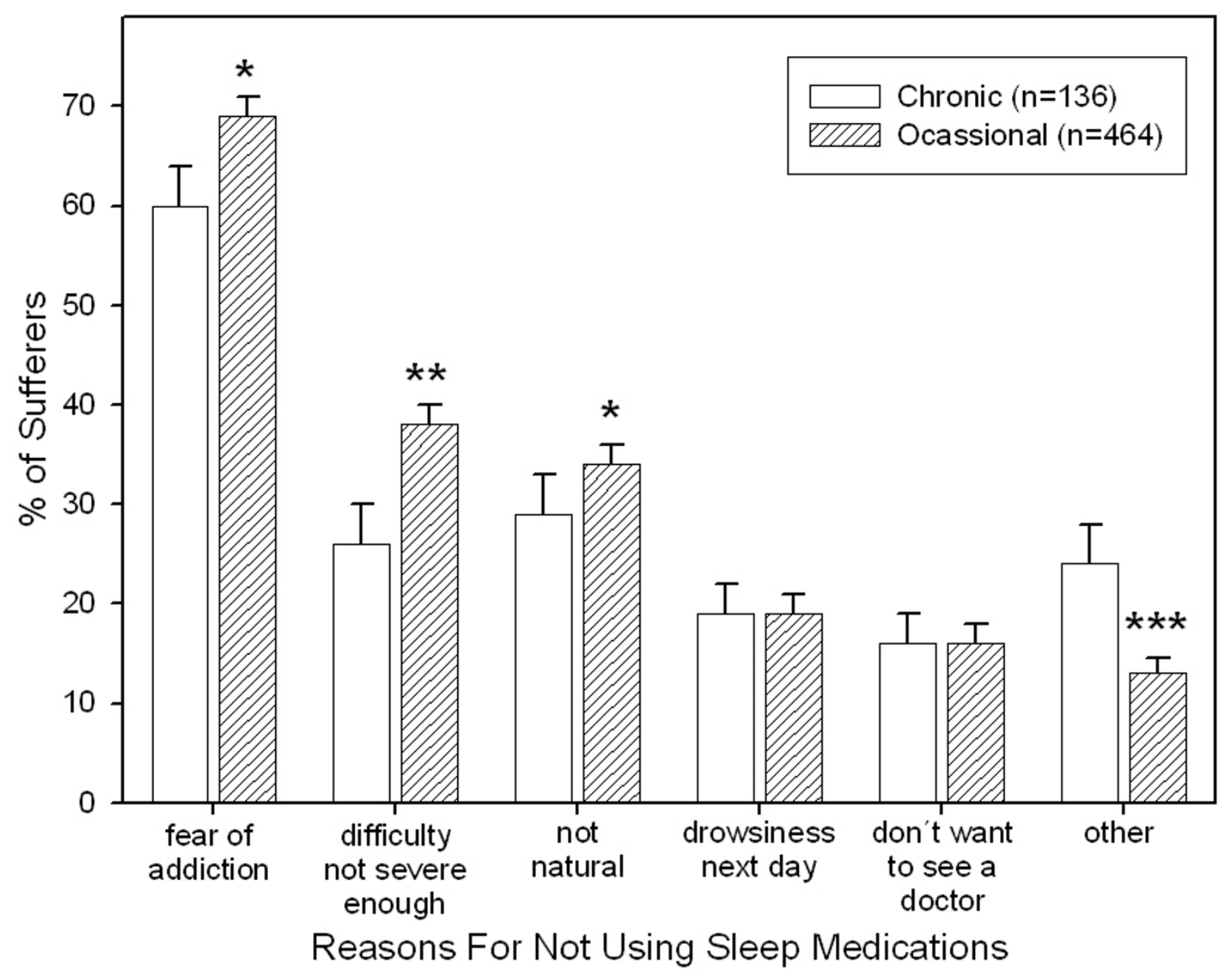

Figure 3

Reasons for not using sleep medication among chronically or occasionally affected subjects. Shown are the means + SEM. ${ }^{*} p<0.05,{ }^{* *} p<0.00$ I and ${ }^{* * *} p<0.000$ I vs. chronically affected sufferers (t-test for proportions).

inform Latin American physicians about the importance of sleep medicine and to train them to treat sleep disturbances adequately is urgently needed.

Low rates of recognition of sleep problems in primary care have been documented. Despite the high prevalence of sleep problems in most studies, e.g. [28-36], evidence suggests that a small minority of cases are identified or diagnosed. For example, one study examined the prevalence of sleep complaints in hospitalized patients in a tertiary care medical center [37]. Although nearly half (47\%) of the patients reported either insomnia or excessive daytime somnolence on a sleep questionnaire, no medical record included any patient symptom related to sleep [37]. Low rates of recognition of sleep problems in primary care were also recorded in a comparison of a community-based versus clinical academic setting [24]. The overall prevalence rate of sleep-related disturbances in the community-based sample was $0.1 \%$ while that in the university-based sample was $3.1 \%$, again a very low rate as compared to several population estimates [28-36]. 


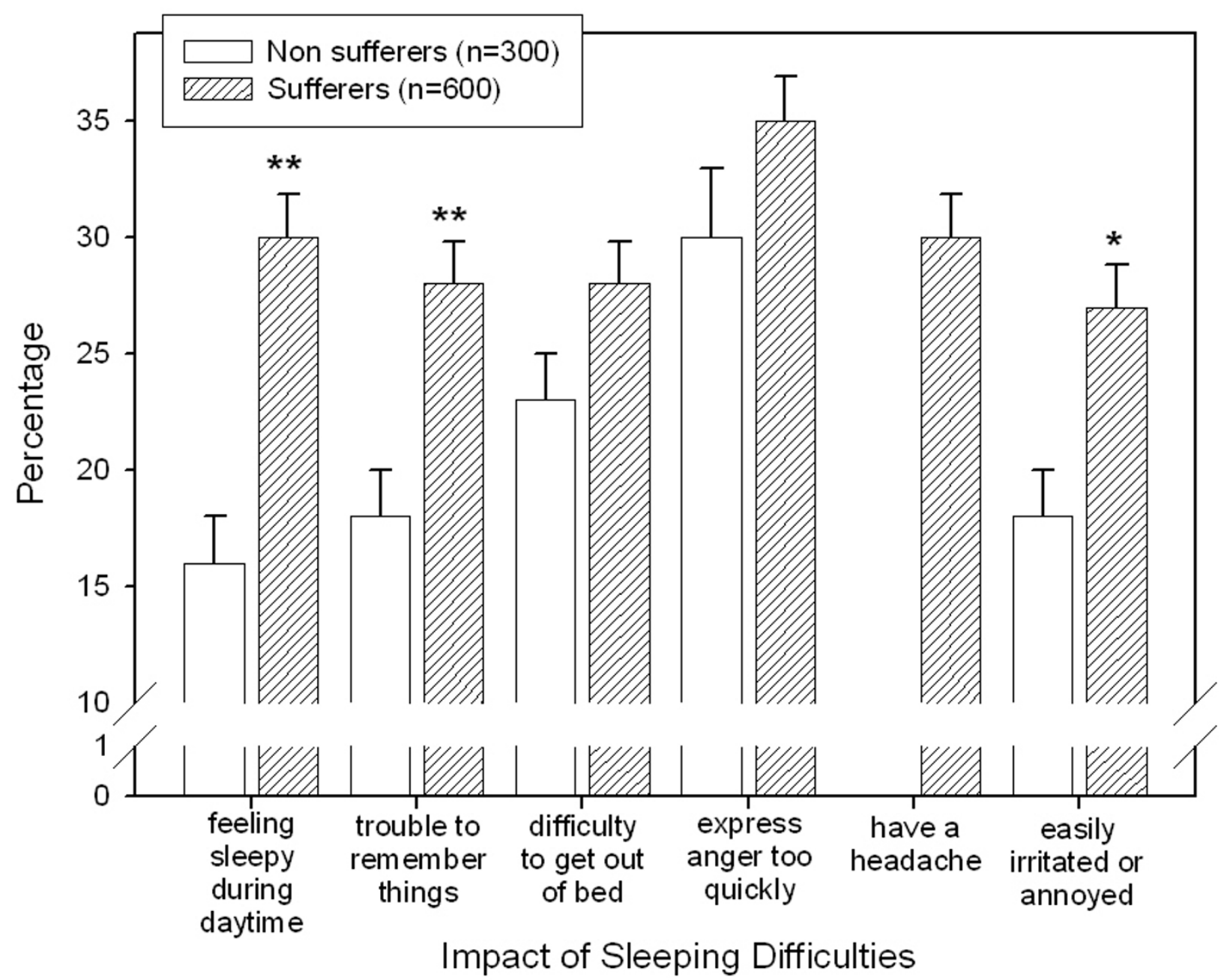

Figure 4

Impact of sleep difficulties over quality of life and daily performance. Shown are the means $+S E M . * p<0.05, * * p<$ 0.001 vs. non-sufferers (t-test for proportions

Several factors might account for the low rate of recognition and diagnosis of sleep disturbances in outpatient healthcare settings. First, the lack of education in sleep in both undergraduate and postgraduate medical training has been documented [19,22-25,38,39]. Secondly, physician and patient attitudes may also play an important role, as sleep is often devalued as a significant healthrelated behavior by large segments of the population. As recently noted [40], solutions to the problem of sleep and fatigue in medical education require the active involvement of numerous parties, ranging from the physicians themselves to training program directors, hospital administrators, sleep researchers and government funding.

Sufferers in the present survey reported diminished quality of life, expressed as daily sleepiness, irritability, headaches and memory alterations. Surprisingly, most sufferers were unwilling to seek medical assistance. In most cases, they adduced that their problem was not serious enough. A discrepancy between subjective observations and objective measures of sleep had previously been shown [41]. Presumably, such a discrepancy accounts for the present observations that sufferers did not usually 
perceive the magnitude of their sleep problem although reporting troubles initiating sleep, frequent awakenings or episodes of daily sleepiness. The finding that most of sufferers were aware that sleep disturbances could lead to impaired daily performance and to health problems and yet they were not willing to seek for medical treatment suggests that a misperception in the appreciation of sleep quality and their impact on life occurs.

A lower rate of self-reported sleep complaints among Hispanic patients, as compared to African or American Caucasian patients, was reported [25]. Differences in cultural practices or attitudes towards sleep were entertained as explanations for fewer sleep difficulties or complaints in the Hispanic population. Our present results on a sleep survey in a predominantly Hispanic population indicate that only $31 \%$ of sufferers sought for medical help while physicians assessed presence of sleep disorder in only 33 $\%$ of those patients consulting them for causes other than sleep problems. Not considering the problem serious enough and fear to become addicted to medication were the reasons for not seeking medical help most frequently mentioned. Therefore, the data obtained did not differ significantly from observations among other ethnic populations [25].

Independently of subjective perceptions, sleep disturbances can be detrimental to overall health. For example, drowsiness during driving, which is an important risk factor for car-related accidents $[15,42]$, was found in the present study in a significantly greater proportion among sufferers as compared to non-sufferers. Educational programs to advice the Latin Americans public about the serious health consequences associated with sleep problems are thus needed.

Nowadays, strategies not involving medication, such as sleep hygiene education, sleep restriction, cognitive therapy or multi-component therapy, have proven to be successful for the treatment of sleep disturbances [43-45]. However, attending physicians tend to favor pharmacological strategies over non-pharmacological ones $[20,46,47]$. This occurs in spite of findings strongly indicating that hypnotics are not beneficial for all sufferers $[3,48]$. Thus it is not a surprise that fear of becoming addicted to prescribed medicine was frequently stated as a cause to avoid seeking for medical help.

In summary, the present study adds evidence to the formerly established concept that sleep disturbances are detrimental to overall health and daily performance, and that they are frequent among general population and remain grossly undiagnosed by general practitioners in urban Latin American areas. The limitations of the present study are worth noting: it is based on self-reports and not on objective measures of sleep and evaluation of physician behavior was based exclusively on a retrospective recall. Keeping this in mind, the present findings help to emphasize the need for increased education and training in sleep disturbances for physicians and other allied health professionals in Latin America. Public educational campaigns on the consequences of sleep disturbances as well as an adequate training of physicians in sleep medicine at a graduate and post-graduate level will help to fade away barriers for the unwillingness of Latin Americans to seek medical attention for their sleep difficulties.

Foregoing results derived from a community-based multinational structured survey on sleep disorders in Latin American urban populations indicated that only a small part of sufferers sought medical help for their disorder or was questioned about them by the attending physician. Although experiencing significantly lower quality of life (i.e. daily sleepiness, trouble remembering things, headaches and irritability) and being more prone to car-related accidents, at least half of sufferers avoided seeking for medical help. Instead, non-medical strategies were employed by 2 out of 3 sufferers.

Sleep disorders are generally overlooked by physicians. For example, when presented with a theoretical standard case of sleep disorder, less than $50 \%$ of physicians employed a sleep history to record the symptoms [21]. Accordingly, we found that only $30 \%$ of sufferers visiting their doctors for causes different to sleep difficulties were surveyed about them. Since these disorders can be easily treated by general practitioners without the need of a specialist [22], an effective educational campaign to inform Latin American physicians about the importance of sleep medicine and to train them to treat sleep disorders adequately is urgently needed.

Sufferers in the present survey reported diminished quality of life, expressed as daily sleepiness, irritability, headaches and memory alterations. Surprisingly, most sufferers were unwilling to seek medical assistance. In most cases, they adduced that their problem was not serious enough. A discrepancy between subjective observations and objective measures of sleep had previously been shown [23]. Presumably, such a discrepancy accounts for the present observations that sufferers did not usually perceive the magnitude of their sleep problem although reporting troubles initiating sleep, frequent awakenings or episodes of daily sleepiness. The finding that most of sufferers were aware that sleep disorders could lead to impaired daily performance and to health problems and yet they were not willing to seek for medical treatment suggests that a misperception in the appreciation of sleep quality and their impact on life occurs. 
Independently of subjective perceptions, sleep disorders can be detrimental to overall health. For example, drowsiness during driving, which is an important risk factor for car-related accidents $[14,24]$, was found in the present study in a significantly greater proportion among sufferers as compared to non-sufferers. Educational programs to advice the Latin Americans public about the serious health consequences associated with sleep disorders are needed.

Nowadays, strategies not involving medication, such as sleep hygiene education, sleep restriction, cognitive therapy or multi-component therapy, have proven to be successful for the treatment of sleep disorders [25-27]. However, attending physicians tend to favor pharmacological strategies over non-pharmacological ones $[20,28,29]$. This occurs in spite of findings strongly indicating that hypnotics are not beneficial for all sufferers $[1,30]$. Thus it is not a surprise that fear of becoming addicted to prescribed medicine was frequently stated as a cause to avoid seeking for medical help.

\section{Conclusions}

The limitations of the present study are worth noting: it is based on self-reports and not on objective measures of sleep and evaluation of physician behavior was based exclusively on a retrospective recall. Keeping this in mind, the present results add evidence to the formerly established concept that sleep disorders are detrimental to overall health and daily performance, are frequent among general population and remain grossly undiagnosed by general practitioners in urban Latin American areas. Public educational campaigns on the consequences of sleep disorders as well as an adequate training of physicians in sleep medicine at a graduate and post-graduate level will help to fade away barriers for the unwillingness of Latin Americans to seek medical attention for their sleep difficulties

\section{Competing interests}

None declared.

\section{Authors' contributions}

MB, DPC and NK, as President, Vice-President and Secretary of the Latin American Sleep Society for the period 1999-2000, were the investigators in charge to coordinate the two phases of door-to-door and telephone interviews. SPLL carried out the statistical analysis and elaboration of conclusions. All authors read and approved the final manuscript.

\section{Acknowledgements}

This work was supported by an educational grant from Wyeth-Ayerst Pharmaceuticals. The authors thank ACNielsen BASES, Covington, Kentucky, USA, for allowing use of the data hereby presented.

\section{References}

I. Mata Ruiz I, Ortiz Lobo A, Hernandex Monsalve $M$ and Gervas J: [Insomnia in general practice: the opinion of the patient and the professional]. Aten Primaria 1995, 16:271-274.

2. Althuis MD, Fredman L, Langenberg PW and Magaziner J: The relationship between insomnia and mortality among community-dwelling older women. J Am Geriatr Soc 1998, 46: I 270-I 273.

3. Ohayon MM, Caulet M, Arbus L, Billard L, Coquerel A, Guieu JD, Kullmann B, Loffont F, Lemoine P and Paty J et al.: Are prescribed medications effective in the treatment of insomnia complaints? J Psychosom Res 1999, 47:359-368.

4. Blais FC, Morin CM, Boisclair A, Grenier V and Guay B: [Insomnia. Prevalence and treatment of patients in general practice]. Can Fam Physician 2001, 47:759-767.

5. Haldemann R, Good M and Holsboer-Trachsler E: [Epidemiological study of sleep disorders in patients in Swiss general practice]. Schweiz Rundsch Med Prax 1996, 85: I 656-I662.

6. Schramm E, Hohagen F, Kappler C, Grasshoff $U$ and Berger M: Mental comorbidity of chronic insomnia in general practice attenders using DSM-III-R. Acta Psychiatr Scand 1995, 91:10-I7.

7. Ohayon MM and Lemoine P: [A connection between insomnia and psychiatric disorders in the French general population]. Encephale 2002, 28:420-428.

8. Koren D, Arnon I, Lavie $P$ and Klein E: Sleep complaints as early predictors of posttraumatic stress disorder: a I-year prospective study of injured survivors of motor vehicle accidents. Am J Psychiatry 2002, I 59:855-857.

9. Rains JC and Penzien DB: Chronic headache and sleep disturbance. Curr Pain Headache Rep 2002, 6:498-504.

10. Kumar S, Bhatia M and Behari M: Sleep disorders in Parkinson's disease. Mov Disord 2002, I 7:775-78I.

II. Punjabi NM, Sorkin JD, Katzel LI, Goldberg AP, Schwartz AR and Smith PL: Sleep-disordered breathing and insulin resistance in middle-aged and overweight men. Am J Respir Crit Care Med 2002, 1 65:677-682.

12. Hermann DM and Bassetti CL: Sleep-disordered breathing and stroke. Curr Opin Neurol 2003, 16:87-90.

13. Eriksen W, Natvig B and Bruusgaard D: Sleep problems: a predictor of long-term work disability? A four-year prospective study. Scand J Public Health 200I, 29:23-3I.

14. Garbarino S, Nobili L, Beelke M, De Carli F and Ferrillo F: The contributing role of sleepiness in highway vehicle accidents. Sleep 200I, 24:203-206.

15. Connor J, Norton R, Ameratunga S, Robinson E, Civil I, Dunn R, Bailey J and Jackson R: Driver sleepiness and risk of serious injury to car occupants: population based case control study. BMJ 2002, 324:II 25.

16. BaHammam AS: Knowledge and attitude of primary health care physicians towards sleep disorders. Saudi Med J 2000, 2 I: I I 64- I I67.

17. Baillargeon L, Demers M, Gregoire JP and Pepin M: [Study on insomnia treatment by family physicians]. Can Fam Physician 1996, 42:426-432.

18. Ohayon MM, Caulet M, Priest RG and Guilleminault C: Psychotropic medication consumption patterns in the UK general population. J Clin Epidemiol 1998, 5 I :273-283.

19. Orr WC, Stahl ML, Dement WC and Reddington D: Physician education in sleep disorders. J Med Educ 1980, 55:367-369.

20. Haponik EF: Sleep disturbances of older persons: physicians' attitudes. Sleep 1992, I 5: 168-172.

21. Haponik EF, Frye AW, Richards B, Wymer A, Hinds A, Pearce K, $\mathrm{McC}$ all $\mathrm{V}$ and Konen J: Sleep history is neglected diagnostic information. Challenges for primary care physicians. J Gen Intern Med 1996, I I:759-76I.

22. Rosen RC, Mahowald M, Chesson A, Doghramji K, Goldberg R, Moline M, Millman R, Zammit G, Mark B and Dement W: The Taskforce 2000 survey on medical education in sleep and sleep disorders. Sleep 1998, 2 I:235-238.

23. Namen AM, Wymer A, Case D and Haponik EF: Performance of sleep histories in an ambulatory medicine clinic: impact of simple chart reminders. Chest 1999, I I 6: I 558-1563.

24. Rosen RC, Zozula R, Jahn EG and Carson JL: Low rates of recognition of sleep disorders in primary care: comparison of a community-based versus clinical academic setting. 200I, 2:47-55. 
25. Namen AM, Landry SH, Case LD, McCall WV, Dunagan DP and Haponik EF: Sleep histories are seldom documented on a general medical service. South Med J 200I, 94:874-879.

26. Everitt DE, Avorn J and Baker MW: Clinical decision-making in the evaluation and treatment of insomnia. Am J Med 1990, 89:357-362.

27. Rakel RE: Insomnia: concerns of the family physician. J Fam Pract 1993, 36:55|-558.

28. Bixler EO, Kales A and Soldatos CR: Sleep disorders encountered in medical practice: a national survey of physicians. Behav Med 1979, 6: |3-2|

29. Ford DE and Kamerow DB: Epidemiologic study of sleep disturbances and psychiatric disorders. An opportunity for prevention? JAMA 1989, 62:|479-| 484.

30. Stradling $\mathrm{JR}$ and Crosby $\mathrm{JH}$ : Predictors and prevalence of obstructive sleep apnoea and snoring in $100 \mathrm{I}$ middle aged men. Thorax 1991, 46:85-90.

31. Young T, Palta M, Dempsey J, Weber S and Badr S: The occurrence of sleep-disordered breathing among middle-aged Adults. $N$ Engl J Med 1993, 328: 1230-1235.

32. Foley DJ, Monjan AA, Brown SL, Simonsick EM, Wallace RB and Blazer DG: Sleep complaints among elderly persons: an epidemiologic study of three communities. Sleep 1995, 18:425-432.

33. Ohayon MM: Epidemiological study on insomnia in the general population. Sleep 1996, 19:7-15.

34. Foley DJ, Monjan A, Simonsick AM, Wallace RB and Blazer DG: Incidence and remission of insomnia among elderly adults: an epidemiologic study of 6,800 persons over three years. Sleep 1999, 22(Suppl 2):S366-S372.

35. Ancoli-lsrael $S$ and Roth $\mathrm{T}$ : Characteristics of insomnia in the United States: results of the 199 I National Sleep Foundation Survey. I. Sleep 1999, 22(Suppl 2):S347-S353.

36. Ohayon MM and Zulley J: Correlates of global sleep dissatisfaction in the German population. Sleep 200I, 24:780-787.

37. Meissner HH, Riemer A, Santiago SM, Stein M, Goldman MD and Williams AJ: Failure of physician documentation of sleep complaints in hospitalized patients. West J Med 1998, I69:146-149.

38. Haponik EF: Sleep disturbances of older persons: physicians' attitudes. Sleep 1992, 15:168-172.

39. Haponik EF, Frye AW, Richards B, Wymer A, Hinds A, Pearce K, McCall $V$ and Konen J: Sleep history is neglected diagnostic information. Challenges for primary care physicians. J Gen Intern Med 1996, I I:759-76I.

40. Buysse DJ, Barzansky B, Dinges D, Hogan E, Hunt CE, Owens J, Rosekind $M$, Rosen R, Simon F and Veasey $S$ et al:: Sleep, fatigue, and medical training: setting an agenda for optimal learning and patient care. Sleep 2003, 26:218-225.

4I. Declerck AC: Is "poor sleep" too vague a concept for rational treatment? J Int Med Res 1994, 22: I- 16.

42. Horne JA and Reyner LA: Sleep related vehicle accidents. $B M J$ 1995, 3 1 0:565-567.

43. Baillargeon $\mathrm{L}$ : [Behavior and cognitive treatments for insomnia. An alternative to pharmacotherapy]. Can Fam Physician 1997, 43:290-6.

44. Espie CA, Inglis SJ, Tessier S and Harvey L: The clinical effectiveness of cognitive behaviour therapy for chronic insomnia implementation and evaluation of a sleep clinic in general medical practice. Behav Res Ther 2001, 39:45-60.

45. Petit L, Azad N, Byszewski A, Sarazan FF and Power B: Non-pharmacological management of primary and secondary insomnia among older people: review of assessment tools and treatments. Age Ageing 2003, 32:19-25.

46. Stoppe G, Sandholzer H, Staedt J, Kiefer J, Winter S and Ruther E: [Ambulatory treatment of sleep disorders in the aged]. Dtsch Med Wochenschr 1994, I 19:1538-1542.

47. Backhaus J, Junghanns K, Mueller-Popkes K, Broocks A, Riemann D, Hajak $G$ and Hohagen F: Short-term training increases diagnostic and treatment rate for insomnia in general practice. Eur Arch Psychiatry Clin Neurosci 2002, 252:99-104.

48. Hohagen F, Rink K, Kappler C, Schramm E, Riemann D, Weyerer S and Berger M: Prevalence and treatment of insomnia in general practice. A longitudinal study. Eur Arch Psychiatry Clin Neurosci 1993, 242:329-336.

\section{Pre-publication history}

The pre-publication history for this paper can be accessed here:

http://www.biomedcentral.com/1471-2296/4/17/prepub
Publish with BioMed Central and every scientist can read your work free of charge

"BioMed Central will be the most significant development for disseminating the results of biomedical research in our lifetime. "

Sir Paul Nurse, Cancer Research UK

Your research papers will be:

- available free of charge to the entire biomedical community

- peer reviewed and published immediately upon acceptance

- cited in PubMed and archived on PubMed Central

- yours - you keep the copyright
BioMedcentral 